\title{
Preoperative Left Atrial Emptying Fraction is a Powerful Predictor of Successful Maze Procedure
}

\author{
Masaru Aikawa, MD; Hiroyuki Watanabe, MD; Tomoki Shimokawa, MD*; Kanki Inoue, MD; \\ Itaru Takamisawa, MD; Atsushi Seki, MD; Tetsuya Tobaru, MD; Nobuo Iguchi, MD; \\ Kazuhiko Misu, MD; Masatoshi Nagayama, MD; Ryuta Asano, MD; \\ Jun Umemura, MD; Shuichiro Takanashi, MD*; Tetsuya Sumiyoshi, MD
}

\begin{abstract}
Background The maze procedure for the treatment of atrial fibrillation (AF) is a widely used adjunctive therapy. It is necessary to define the precise indications for the procedure based on preoperative factors, but definitive parameters in terms of atrial function have not been well determined.

Methods and Results In the present study, 55 consecutive patients undergoing the maze procedure for persistent AF in combination with operations for organic heart diseases were evaluated. After dividing the patients into successful $(n=41)$ and unsuccessful procedure $(n=14)$ groups, based on the postoperative rhythm, the preoperative left atrial (LA) emptying fraction measured by transthoracic 2-dimensional echocardiogram was compared between groups. The LA emptying fraction was calculated as [(LA maximum volume-LA minimum volume)/ LA maximum volume $] \times 100$. The preoperative LA emptying fraction was higher in the successful procedure group than in the unsuccessful procedure group $(31.2 \pm 8.5 \mathrm{vs} 21.4 \pm 10.9 \%, \mathrm{P}=0.0011)$. Based on receiver-perating characteristic curve analyses, LA emptying fraction $>26 \%$ predicted successful maze procedure with $70.7 \%$ sensitivity and $78.6 \%$ specificity.
\end{abstract}

Conclusions LA emptying fraction should be considered in the precise indications of the maze procedure as adjunctive therapy. (Circ J 2009; 73: 269-273)

Key Words: Atrial fibrillation; Left atrial emptying fraction; Maze

$\mathbf{T}$

he deleterious effects of atrial fibrillation (AF) include loss of effective atrial contraction and atrioventricular synchrony, which may compromise hemodynamic performance and cause stasis of blood flow within the atrium that lead thrombus formation and systemic thromboembolic complications. In addition, a persistently elevated ventricular rate during $\mathrm{AF}$ may produce dilated ventricular cardiomyopathy (tachycardia-induced cardiomyopathy) $)^{1,2}$

The maze procedure for the treatment of AF is widely performed as adjunctive therapy in patients undergoing operations for organic heart diseases? However, from a surgical point of view, it is a demanding procedure that prolongs the aortic cross-clamp and operating times. Therefore, it is necessary to define the precise indications of the maze procedure based on preoperative factors.

The duration of AF and the left atrial (LA) size have been reported as predictors of successful maze procedure,-8 as has the AF wave voltage on electrocardiography (ECG);4,5,7 however, definitive parameters in terms of atrial function for the maze procedure have not been well determined.

The LA emptying fraction has been widely used as an index of LA function? so the goal of this study was to de-

(Received April 4, 2008; revised manuscript received October 1, 2008; accepted October 3, 2008; released online December 18, 2008) Department of Cardiology, *Department of Cardiovascular Surgery, Sakakibara Heart Institute, Fuchu, Japan

Mailing address: Hiroyuki Watanabe, MD, Department of Cardiology, Sakakibara Heart Institute, 3-16-1 Asahi-cho, Fuchu 183-0003, Japan. E-mail: hwatana@shi.heart.or.jp

All rights are reserved to the Japanese Circulation Society. For permis-

sions, please e-mail: cj@j-circ.or.jp termine whether it predicts successful maze procedure.

\section{Methods}

\section{Study Population}

Between March 2004 and February 2007, we evaluated 55 consecutive patients ( 42 men; aged $62 \pm 10$ years; range, $37-78$ years) who underwent the maze procedure for persistent $\mathrm{AF}$ in conjunction with other operations for organic heart diseases at Sakakibara Heart Institute. Persistent AF was defined as a state of continuous AF 10 The mean duration of AF before operation was 4.3 \pm 5.1 years (range, $0.2-$ 26 years). The mean preoperative resting heart rate was 62 beats/min (range, 47-94 beats $/ \mathrm{min}$ ). The mean left ventricular (LV) ejection fraction was $59 \pm 10 \%$ (range, 29$75 \%)$.

The maze procedure is fundamentally the same as that initially described by Cox? ${ }^{80} \mathrm{~A}$ maze-like series of incisions is created in the left and right atria. During the operation, the pulmonary veins are completely isolated, and the LA and right atrial appendages are removed. In the present study, the most common concomitant cardiac procedure was mitral valve plasty for mitral regurgitation (Table 1).

\section{Study Design}

We retrospectively reviewed the data from operative notes, clinical case histories, and laboratory investigations, including ECGs and echocardiograms. Follow-up data were collected from the outpatient records of Sakakibara Heart Institute and correspondence with the physicians to whom the patients were referred. After hospital discharge, patients were followed up monthly for adjustment of medication and 
Table 1 Concomitant Cardiac Procedures

\begin{tabular}{|c|c|c|}
\hline & $\begin{array}{c}\text { Successful procedure } \\
(n=41)\end{array}$ & $\begin{array}{c}\text { Unsuccessful procedure } \\
(n=14)\end{array}$ \\
\hline$M V P$ for $M R, n(\%)$ & $12(29.3)$ & $3(21.4)$ \\
\hline$M V P$ for $M R+A S D$ closure $+T A P$ for $T R, n(\%)$ & $2(4.9)$ & $1(7.1)$ \\
\hline$M V P$ for $M R+C A B G, n(\%)$ & $2(4.9)$ & $1(7.1)$ \\
\hline$M V P$ for $M R+L V P, n(\%)$ & $0(0)$ & $1(7.1)$ \\
\hline$M V P$ for $M R+T A P$ for $T R, n(\%)$ & $4(9.8)$ & $1(7.1)$ \\
\hline$M V R$ for $M R, n(\%)$ & $2(4.9)$ & $0(0)$ \\
\hline$M V R$ for $M R+T A P$ for $T R, n(\%)$ & $2(4.9)$ & $1(7.1)$ \\
\hline$M V R$ for $M S+T A P$ for $T R, n(\%)$ & $1(2.4)$ & $1(7.1)$ \\
\hline$M V R$ for $M S R, n(\%)$ & $0(0)$ & $4(28.6)$ \\
\hline$M V R$ for $M S R+A V R$ for $A S, n(\%)$ & $1(2.4)$ & $0(0)$ \\
\hline$M V R$ for $M S R+A V R$ for $A S R, n(\%)$ & $1(2.4)$ & $0(0)$ \\
\hline$M V R$ for $M S R+T A P$ for $T R, n(\%)$ & $3(7.3)$ & $0(0)$ \\
\hline$A V R$ for $A R, n(\%)$ & $3(7.3)$ & $0(0)$ \\
\hline AVR for $A S, n(\%)$ & $2(4.9)$ & $0(0)$ \\
\hline$A V R$ for $A R+V S D$ closure $+C A B G, n(\%)$ & $1(2.4)$ & $0(0)$ \\
\hline ASD closure + TAP for TR, $n(\%)$ & $4(9.8)$ & $1(7.1)$ \\
\hline$C A B G, n(\%)$ & $1(2.4)$ & $0(0)$ \\
\hline
\end{tabular}

$M V P$, mitral valve plasty; $M R$, mitral regurgitation; ASD, atrial septal defect; TAP, tricuspid annuloplasty; TR, tricuspid regurgitation; $C A B G$, coronary artery bypass grafting; $L V P$, left ventricle plasty; MVR, mitral valve replacement; $M S$, mitral stenosis; MSR, mitral stenosis and regurgitation; AVR, aortic valve replacement; AS aortic stenosis; ASR, aortic stenosis and regurgitation; AR, aortic regurgitation; VSD, ventricular septal defect.
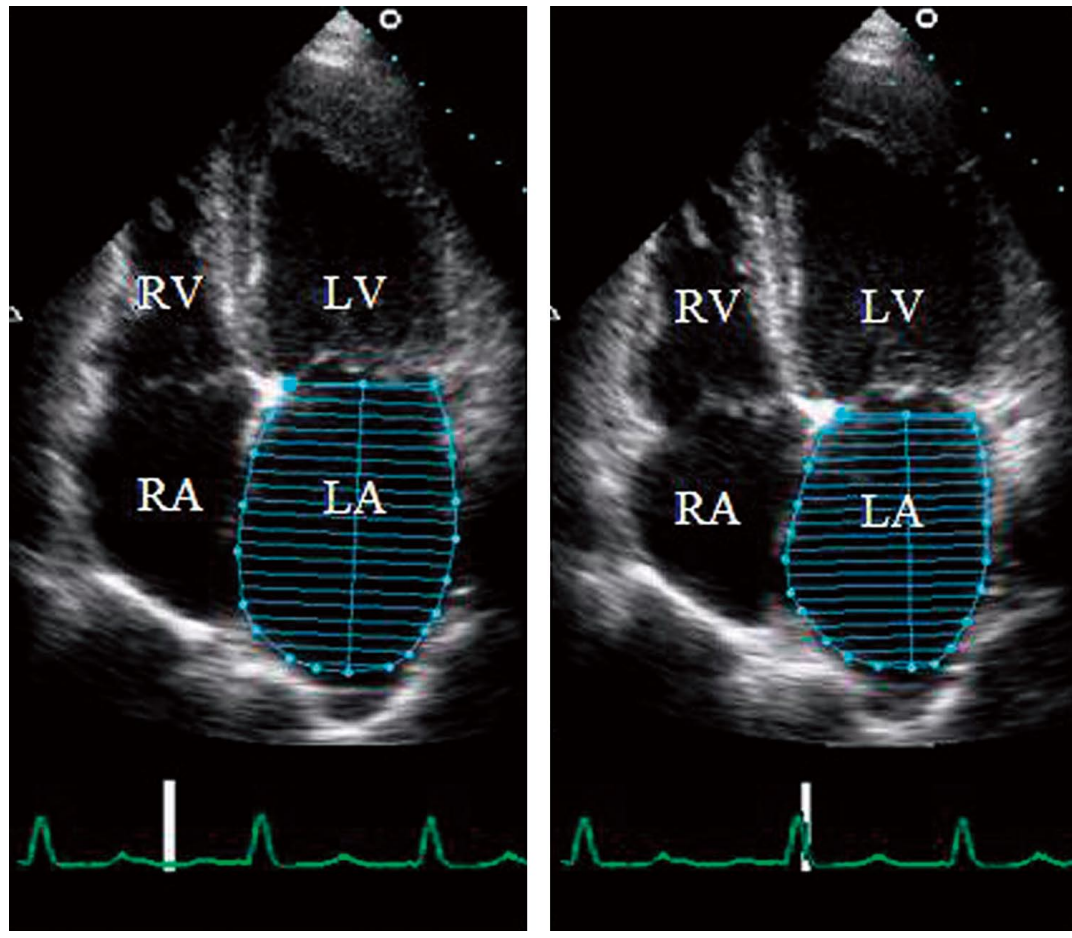

Fig 1. Measurement of LA volumes in the apical 4-chamber view immediately before mitral valve opening (LA maximum volume, Left) and at mitral valve closure (LA minimum volume, Right) according to the method of discs. LA, left atrium; LV, left ventricle; RA, right atrium; $\mathrm{RV}$, right ventricle. evaluation of cardiac rhythm. The recommended interval of 12-lead ECG follow-up was 3 months. Holter ECGs were performed at the discretion of the attending physicians.

An unsuccessful maze procedure was defined as the occurrence of any ECG-documented AF or atrial flutter, including transient events, more than 3 months after the operation. After dividing the patients into a successful procedure group and an unsuccessful procedure group based on the postoperative rhythm, we compared various parameters between the 2 groups? 71

All patients provided written informed consent before participating in the study, which was approved by the Sakakibara Heart Institute Ethics Committee.

\section{Echocardiography}

Comprehensive 2-dimensional echocardiographic views were recorded before operation with a Sonos 7500 (Philips Medical Systems, Andover, MA, USA) with an S3 transducer. All off-line analyses were performed with Xcelera (Philips Medical Systems) and all analyses were based on the average values obtained from measurements of more than 6 beats. ${ }^{12-15}$

The LA dimension was obtained from M-mode echocardiography in the parasternal long-axis view according to the guideline of the American Society of Echocardiography! 16,17 The volumes of the LA and LV were measured by manually drawing the endocardial boundaries of the cavities 
Table 2 Clinical Characteristics

\begin{tabular}{lccc}
\hline \hline & $\begin{array}{c}\text { Successful procedure } \\
(n=41)\end{array}$ & $\begin{array}{c}\text { Unsuccessful procedure } \\
(n=14)\end{array}$ & P value \\
\hline Age, years & $60 \pm 11$ & $67 \pm 7$ & 0.0323 \\
Male, $n(\%)$ & $33(80.5)$ & $9(64.3)$ & 0.3819 \\
Duration of AF, years & $4.3 \pm 5.3$ & $4.2 \pm 4.6$ & 0.9356 \\
Heart rate, beats/min & $77 \pm 16$ & $81 \pm 12$ & 0.3117 \\
Hypertension, $n(\%)$ & $13(31.7)$ & $2(14.3)$ & 0.3563 \\
Diabetes, $n(\%)$ & $3(7.3)$ & $0(0)$ & 0.7991 \\
Renal insufficiency $(C r>2.0 \mathrm{mg} / \mathrm{dl}), n(\%)$ & $0(0)$ & $2(14.3)$ & 0.0982 \\
BNP, pg/ml & $308 \pm 247$ & $282 \pm 169$ & 0.7138 \\
NYHA functional class & & & 0.8841 \\
I, $n(\%)$ & $9(22.0)$ & $4(28.6)$ & \\
II, $n(\%)$ & $17(41.5)$ & $5(35.7)$ & \\
III, $n(\%)$ & $14(34.1)$ & $4(28.6)$ & \\
$I V, n(\%)$ & $1(2.4)$ & $1(7.1)$ & \\
\hline
\end{tabular}

$A F$, atrial fibrillation; $C r$, creatinine; BNP, brain natriuretic peptide; NHYA, New York Heart Association.

Table 3 Echocardiographic Parameters

\begin{tabular}{lccc}
\hline \hline & $\begin{array}{c}\text { Successful procedure } \\
(\mathrm{n}=41)\end{array}$ & $\begin{array}{c}\text { Unsuccessful procedure } \\
(\mathrm{n=14})\end{array}$ & P value \\
\hline LA dimension, $\mathrm{mm}$ & $54.6 \pm 9.3$ & $53.4 \pm 6.9$ & 0.6749 \\
LA maximum volume index, $\mathrm{ml} / \mathrm{m}^{2}$ & $91.4 \pm 37.6$ & $92.0 \pm 37.5$ & 0.9603 \\
LA minimum volume index, $\mathrm{ml} / \mathrm{m}^{2}$ & $63.1 \pm 27.4$ & $71.9 \pm 29.0$ & 0.3151 \\
LA emptying fraction, \% & $31.2 \pm 8.5$ & $21.4 \pm 10.9$ & 0.0011 \\
LV end-diastolic volume index, $\mathrm{ml} / \mathrm{m}^{2}$ & $80.9 \pm 32.1$ & $79.9 \pm 40.1$ & 0.9202 \\
LV end-systolic volume index, $\mathrm{ml} / \mathrm{m}^{2}$ & $33.0 \pm 17.3$ & $34.3 \pm 18.4$ & 0.8097 \\
LV ejection fraction, $\%$ & $60.2 \pm 10.0$ & $57.4 \pm 9.0$ & 0.3574 \\
LV mean wall thickness, $\mathrm{mm}$ & $10.4 \pm 1.2$ & $9.9 \pm 0.8$ & 0.1214 \\
\hline
\end{tabular}

$L A$, left atrium; $L V$, left ventricle.

according to the method of discs in the apical 4-chamber view, and were corrected by body surface area ${ }^{17,18}$

LA volume was measured immediately before mitral valve opening (LA maximum volume) and at mitral valve closure (LA minimum volume) $)^{17,19}$ The pulmonary veins and LA appendage, when visualized, were excluded from the outlines (Fig 1) ${ }^{17,20}$ To evaluate LA function, the LA emptying fraction was calculated as [(LA maximum volume-LA minimum volume)/LA maximum volume $\times 100$ ?

The LV end-diastolic volume, LV end-systolic volume, and LV ejection fraction were obtained according to the guideline of the American Society of Echocardiography 18 LV mean wall thickness was determined as the average of the posterior and septal wall thicknesses measured from the parasternal long-axis view.

Re-analysis of the LA maximum volume, LA minimum volume, and LA emptying fraction was performed in 15 randomly selected participants by the same observer and also by a second observer on separate occasions but using the same recordings. Intra- and interobserver variabilities were assessed as mean percent error (absolute difference divided by the average of the 2 observations).

\section{ECG}

Standard 12-lead ECG was performed in each patient before operation. All ECGs were standardized to normal speed $(25 \mathrm{~mm} / \mathrm{min})$ and sensitivity $(1 \mathrm{mV}$ input produced a 10 -mm deflection). The AF wave with the greatest size was measured in lead $\mathrm{V}_{1}$ for at least 6 cardiac cycles. It was measured from the upper edge of the peak to the upper edge of the trough? ${ }^{2}$

\section{Statistical Analysis}

Continuous variables are reported as mean \pm standard deviation, and categorical variables are reported as number and percentages. Comparisons between groups were made with the chi-square test or Fisher's exact test for categorical variables and Student's t-test for continuous variables. The significance of multiple variables found significant in the univariate analysis was determined using multiple logistic regression analysis. The optimal cut-off points were determined by receiver-operating characteristic curves analysis. A P-value less than 0.05 was considered to be significant. All statistical analyses were performed with SPSS software version 11.0 (SPSS Inc, Chicago, IL, USA).

\section{Results}

\section{Clinical Follow-up}

Clinical follow-up was achieved in all patients (mean duration, $14.7 \pm 8.0$ months). No deaths occurred during the follow-up period. One (2\%) patient had a pacemaker implanted for sick sinus syndrome at 3 months after the operation.

At 3 months after operation, 46 (84\%) patients were free from $\mathrm{AF}$ and atrial flutter. At the last follow-up, 41 (75\%) patients remained free from AF and atrial flutter (successful procedure group) and $14(25 \%)$ patients continued to have $\mathrm{AF}$ or atrial flutter (unsuccessful procedure group).

In the successful procedure group, $4(10 \%)$ patients were on cibenzoline, $1(2 \%)$ was on pilsicainide, $2(5 \%)$ were on amiodarone, $20(49 \%)$ were on $\beta$-blockers, $16(39 \%)$ were on angiotensin-receptor blockers and/or angiotensin-converting enzyme inhibitors, 10 (24\%) were on calcium channel 


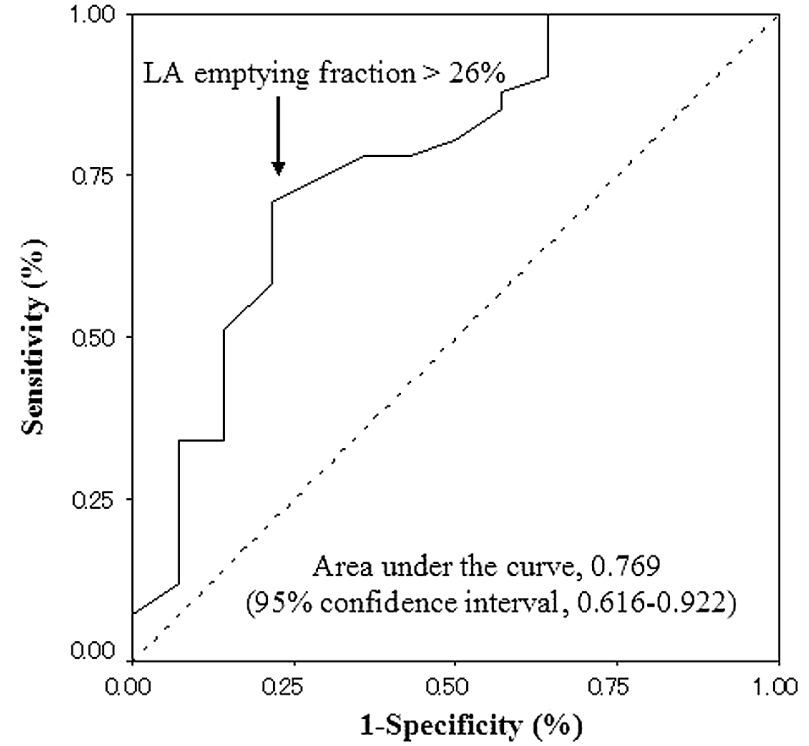

Fig 2. Receiver-operating characteristic curve of the LA emptying fraction for the prediction of successful maze procedure as an adjunctive therapy for persistent atrial fibrillation. Area under the curve was 0.769 (95\% confidence interval, 0.616-0.922) and the optimal cut-off value for successful maze procedure was $26 \%$. LA, left atrium.

blockers, and $5(12 \%)$ was on digitalis.

\section{Clinical Characteristics}

The successful procedure group was younger than the unsuccessful procedure group $(60 \pm 11$ vs $67 \pm 7$ years, $\mathrm{P}=0.0323)$ (Table 2). There were no statistically significant differences between the 2 groups regarding sex, duration of AF, heart rate, the prevalence of hypertension, diabetes, renal insufficiency (creatinine $>2.0 \mathrm{mg} / \mathrm{dl}$ ), plasma brain natriuretic peptide level, or New York Heart Association functional class.

\section{Echocardiography}

The LA emptying fraction was higher in the successful procedure group than in the unsuccessful procedure group (31.2 \pm 8.5 vs $21.4 \pm 10.9 \%, \mathrm{P}=0.0011$ ) (Table 3). The remaining echocardiographic parameters of LA dimension, LA maximum volume index, LA minimum volume index, LV end-diastolic volume index, LV end-systolic volume index, LV ejection fraction and LV mean wall thickness did not differ between the 2 groups.

Intraobserver variabilities for LA maximum volume index, LA minimum volume index and LA emptying fraction were $5.7 \pm 4.2 \%, 7.1 \pm 5.9 \%$ and $10.3 \pm 8.3 \%$, respectively, and the interobserver variabilities were $6.8 \pm 5.2 \%, 7.6 \pm 6.0 \%$ and $13.6 \pm 11.1 \%$, respectively.

\section{$E C G$}

There was no statistically significant difference between the 2 groups in the AF wave voltage in lead $\mathrm{V}_{1}(0.16 \pm$ $0.10 \mathrm{mV}$ vs $0.18 \pm 0.11 \mathrm{mV}, \mathrm{P}=0.4196$ ).

\section{Predictor of Successful Maze Procedure}

According to multiple logistic regression analysis, the preoperative LA emptying fraction was related to successful maze procedure $(\mathrm{P}=0.0024)$ and age was unrelated to successful maze procedure $(\mathrm{P}=0.0722)$.
Using receiver-operating characteristic curve analyses, a preoperative LA emptying fraction $>26 \%$ predicted successful maze procedure with $70.7 \%$ sensitivity and $78.6 \%$ specificity (area under curve $=0.769,95 \%$ confidence interval 0.616-0.922) (Fig 2).

\section{Discussion}

We evaluated 55 consecutive patients to define the precise indications of the maze procedure as an adjunctive therapy. During an average follow-up of 15 months, 41 (75\%) patients remained free from $\mathrm{AF}$ and atrial flutter. Only the preoperative LA emptying fraction significantly influenced the success of the maze procedure. LA emptying fraction greater than $26 \%$ predicted successful maze procedure with $70.7 \%$ sensitivity and $78.6 \%$ specificity. To our knowledge, this is the first study suggesting that the preoperative LA emptying fraction is a useful and powerful predictor of a successful maze procedure.

Prolonged AF results in loss of atrial muscle mass and fibrotic changes within the atrial myocardium?22-25 The combination of mitral valve disease and atrial inflammation secondary to rheumatic carditis causes fibrosis of the atrial wall and disorganization of the atrial muscle bundles,.26 Patients who have mild fibrosis respond more successfully to cardioversion than those with severe fibrosis ${ }^{27}$ so we assume that the LA emptying fraction mirrors the degree of structural change in the LA.

Low $\mathrm{AF}$ wave voltage in the $\mathrm{V}_{1}$ lead has been reported as a predictor of unsuccessful maze procedure, $, 5,7$ but its predictive value was not documented in our study. A decrease in the voltage of AF waves on the 12-lead ECG correlates with the extent of atrial fibrosis; ${ }^{28}$ however, the voltage on the 12-lead ECG is influenced by physiological conditions such as subcutaneous fat and the presence of fluid and gas in the thoracic cavity. Thus, a more precise and robust determinant that represents atrial function is needed.

The LA emptying fraction has been widely used as an index of LA mechanical function? and in this study, the preoperative LA emptying fraction measured by transthoracic 2-dimensional echocardiography was demonstrated to be a powerful predictor of a successful maze procedure and can easily be used as a predictor to decide the indication of the maze procedure as an adjunctive therapy for persistent AF.

\section{Study Limitations}

First, patients with longstanding AF and those with extremely enlarged LA were excluded from our retrospective study according to the surgeon's decision. We expect that the duration of AF and the LA size could be predictors of successful maze procedure if these patients had not been excluded from the study. The mean duration of AF was 4.3 years (range, $0.2-26$ years) in patients with successful maze procedure and 4.2 years (range, $0.3-17$ years) in patients with unsuccessful maze procedure, which was relatively shorter in than previous studies:-8 At the same time, the mean LA dimension was $55 \mathrm{~mm}$ (range, $35-74 \mathrm{~mm}$ ) in patients with successful maze procedure and $53 \mathrm{~mm}$ (range, $42-68 \mathrm{~mm}$ ) in patients with unsuccessful maze procedure and these measurements were smaller than in previous studies.-7

Second, the efficacy of the maze procedure was only $75 \%$ in the present study. Other investigators report long-term success rates of maze procedure in excess of $90 \% \%^{4-6,8,10}$ The explanation for this discrepancy may be related to the 
differences in the study population and perioperative strategy. Although most previous studies investigated patient groups with both persistent and paroxysmal $\mathrm{AF}$, the present study investigated only patients with persistent AF.

Third, the functional effect of the maze procedure was not evaluated by the LA emptying fraction after operation. The time course of the LA emptying fraction must have some influence on the occurrence of AF or atrial flutter after the operation. Further study is needed to clarify this and its relationship to the occurrence of AF or atrial flutter after operation during the follow-up period.

\section{Conclusions}

The preoperative LA emptying fraction was significantly related to the success of the maze procedure in the present study. Preoperative LA emptying fraction greater than $26 \%$ predicted successful maze procedure with $70.7 \%$ sensitivity and $78.6 \%$ specificity, so it should be taken into consideration in defining the precise indications of the maze procedure as an adjunctive therapy for persistent AF.

\section{Disclosures}

None.

\section{Statement of Responsibility}

The authors had full access to the data and take full responsibility for its integrity. All authors have read and agree to the manuscript as written.

\section{References}

1. Packer DL, Bardy GH, Worley SJ, Smith MS, Cobb FR, Coleman RE, et al. Tachycardia-induced cardiomyopathy: A reversible form of left ventricular dysfunction. Am J Cardiol 1986; 57: 563-570.

2. Fujino T, Yamashita T, Suzuki S, Sugiyma H, Sagara K, Sawada H, et al. Characteristics of congestive heart failure accompanied by atrial fibrillation with special reference to tachycardia-induced cardiomyopathy. Circ J 2007; 71: 936-940.

3. Bando K, Kobayashi J, Kosakai Y, Hirata M, Sasako Y, Nakatani S, et al. Impact of Cox maze procedure on outcome in patients with atrial fibrillation and mitral valve disease. J Thorac Cardiovasc Surg 2002; 124: $575-583$.

4. Kamata J, Kawazoe K, Izumoto H, Kitahara H, Shiina Y, Sato Y, et al. Predictors of sinus rhythm restoration after Cox maze procedure concomitant with other cardiac operations. Ann Thorac Surg 1997; 64: $394-398$

5. Isobe F, Kawashima Y. The outcome and indications of the Cox maze III procedure for chronic atrial fibrillation with mitral valve disease. J Thorac Cardiovasc Surg 1998; 116: 220-227.

6. Kosakai Y, Kawaguchi AT, Isobe F, Sasako Y, Nakano K, Eishi K, et al. Cox maze procedure for chronic atrial fibrillation associated with mitral valve disease. J Thorac Cardiovasc Surg 1994; 108: $1049-1054$

7. Kobayashi J, Kosakai Y, Nakano K, Sasako Y, Eishi K, Yamamoto F. Improved success rate of the maze procedure in mitral valve disease by new criteria for patients' selection. Eur J Cardiothorac Surg 1998; 13: $247-252$.

8. Gaynor SL, Schuessler RB, Bailey MS, Ishii Y, Boineau JP, Gleva MJ, et al. Surgical treatment of atrial fibrillation: Predictors of late recurrence. J Thorac Cardiovasc Surg 2005; 129: 104-111.

9. Triposkiadis F, Tentolouris K, Androulakis A, Trikas A, Toutouzas K, Kyriakidis M, et al. Left atrial mechanical function in the healthy elderly: New insights from a combined assessment of changes in atrial volume and transmitral flow velocity. J Am Soc Echocardiogr 1995; 8: 801-809.

10. Prasad SM, Maniar HS, Camillo CJ, Schuessler RB, Boineau JP, Sundt TM 3rd, et al. The Cox maze III procedure for atrial fibrillation: Long-term efficacy in patients undergoing lone versus concomitant procedures. J Thorac Cardiovasc Surg 2003; 126: 1822-1828.

11. Ad N, Barnett S, Lefrak EA, Korach A, Pollak A, Gilon D, et al. Impact of follow-up on the success rate of the cryosurgical maze procedure in patients with rheumatic heart disease and enlarged atria. J Thorac Cardiovasc Surg 2006; 131: 1073-1079.

12. Chen MC, Chang JP, Chang HW. Preoperative atrial size predicts the success of radiofrequency maze procedure for permanent atrial fibrillation in patients undergoing concomitant valvular surgery. Chest 2004; 125: 2129-2134.

13. Chen MC, Chang JP, Chang HW, Chen CJ, Yang $\mathrm{CH}$, Chen $\mathrm{YH}$, et al. Clinical determinants of sinus conversion by radiofrequency maze procedure for persistent atrial fibrillation in patients undergoing concomitant mitral valvular surgery. Am J Cardiol 2005; 96: 1553-1557.

14. Tops LF, Bax JJ, Zeppenfeld K, Jongbloed MR, van der Wall EE, Schalij MJ. Effect of radiofrequency catheter ablation for atrial fibrillation on left atrial cavity size. Am J Cardiol 2006; 97: 1220-1222.

15. Tsang TS, Abhayaratna WP, Barnes ME, Miyasaka Y, Gersh BJ, Bailey KR, et al. Prediction of cardiovascular outcomes with left atrial size: Is volume superior to area or diameter? J Am Coll Cardiol 2006; 47: $1018-1023$.

16. Sahn DJ, DeMaria A, Kisslo J, Weyman A. Recommendations regarding quantitation in M-mode echocardiography: Results of a survey of echocardiographic measurements. Circulation 1978; 58: $1072-1083$.

17. Yamaguchi K, Tanabe K, Tani T, Yagi T, Fujii Y, Konda T, et al. Left atrial volume in normal Japanese adults. Circ J 2006; 70: 285 288.

18. Gottdiener JS, Bednarz J, Devereux R, Gardin J, Klein A, Manning WJ, et al. American Society of Echocardiography recommendations for use of echocardiography in clinical trials. J Am Soc Echocardiogr 2004; 17: 1086-1119.

19. Mattioli AV, Sansoni S, Lucchi GR, Mattioli G. Serial evaluation of left atrial dimension after cardioversion for atrial fibrillation and relation to atrial function. Am J Cardiol 2000; 85: 832-836.

20. Kircher B, Abbott JA, Pau S, Gould RG, Himelman RB, Higgins CB, et al. Left atrial volume determination by biplane two-dimensional echocardiography: Validation by cine computed tomography. Am Heart J 1991; 121: 864-871.

21. Peter RH, Morris JJ Jr, McIntosh HD. Relationship of fibrillatory waves and $\mathrm{P}$ waves in the electrocardiogram. Circulation 1966; 33: 599-606.

22. Saito T, Tamura K, Uchida D, Saito T, Togashi M, Nitta T, et al. Histopathological features of the resected left atrial appendage as predictors of recurrence after surgery for atrial fibrillation in valvular heart disease. Circ J 2007; 71: 70-78.

23. Henry WL, Morganroth J, Pearlman AS, Clark CE, Redwood DR, Itscoitz SB, et al. Relation between echocardiographically determined left atrial size and atrial fibrillation. Circulation 1976; 53: 273-279.

24. Davies MJ, Pomerance A. Pathology of atrial fibrillation in man. $\mathrm{Br}$ Heart J 1972; 34: 520-525.

25. Sanfilippo AJ, Abascal VM, Sheehan M, Oertel LB, Harrigan P, Hughes RA, et al. Atrial enlargement as a consequence of atrial fibrillation: A prospective echocardiographic study. Circulation 1990; 82: $792-797$.

26. Yashima N, Nasu M, Kawazoe K, Hiramori K. Serial evaluation of atrial function by Doppler echocardiography after the maze procedure for chronic atrial fibrillation. Eur Heart J 1997; 18: 496-502.

27. Bailey GW, Braniff BA, Hancock EW, Cohn KE. Relation of left atrial pathology to atrial fibrillation in mitral valvular disease. Ann Intern Med 1968; 69: 13-20.

28. Hirosawa K, Sekiguchi M, Kasanuki H, Kimata S, Kaneko N, Nakamura K, et al. Natural history of atrial fibrillation. Heart Vessels Suppl 1987; 2: 14-23. 